5. Wolfe, D.W., Scopelliti, J.A. \& Boselli, B.D. Leukemic meningitis in a patient with hairy cell leukaemia (case report). Cancer 1984, 54: 1085-1087.

6. Plendreith, I.H. Hairy cell leukemia. Can Med Assoc J 1978, 102: $1056-1060$.

7. Cotelingam, J.D., Knop, R.H., Garvin, D.F., Mercado, T.C. \& Schumacher, H.R. Hairy cell leukemia. N Engl J Med 1983, 308: 47.
8. Knecht, H., Rhyner, K. \& Streuli, R.A. Toxoplasmosis in hairy cell leukemia. Br J Haematol 1986, 62: 65-73.

9. Westbrook, C.A. \& Golde, D.W. Autoimmune disease in hairy cell leukemia: clinical syndromes and treatment. $\mathrm{Br} J$ Haematol 1985, 61: 349-356.

10. Farcet, J.-P., Wechsler, J., Wirquin, V., Divine, M. \& Reyes, F. Vasculitis in hairy cell leukemia. Arch Intern Med 1987, 147: $660-664$.

\title{
Haemolytic-uraemic syndrome with thrombotic microangiopathy of the retina following cytomegalovirus infection: postmortem findings
}

\author{
Blanca Catón, Ramón Díaz de Otazu, Mikel Aldamiz-Echebarria and Amparo \\ Viguri
}

Departments of Pathology and Internal Medicine, Hospital Txagorritxu, 01009 Vitoria, Spain

\begin{abstract}
Summary: Haemolytic-uraemic syndrome is characterized by thrombotic microangiopathy of the glomeruli and smaller arterial vessels of the kidney. Extrarenal thrombotic microangiopathy occurs, but ocular involvement is rarely demonstrated microscopically. We describe a 33 year old woman with a 3 week febrile episode and seropositivity for cytomegalovirus infection who developed acute renal failure, blindness and severe encephalopathy which was the cause of death. Thrombotic microangiopathy of retinal vessels may be more common than is expected from the literature. The exclusion of ocular structures in postmortem examinations explains the lack of anatomoclinical correlation.
\end{abstract}

\section{Introduction}

The haemolytic-uraemic syndrome is a clinical entity, defined by microangiopathic haemolytic anaemia, thrombocytopenia and acute renal failure, whose underlying histopathological feature, thrombotic microangiopathy, is also found in thrombotic thrombocytopenic purpura. ${ }^{1-3}$ Haemolytic-uraemic syndrome and thrombotic thrombocytopenic purpura are considered by some authors ${ }^{1}$ as a different clinical expression of the same disease. Thrombotic microangiopathy always involves the glomeruli and smaller arterial vessels of the kidney, but sometimes spares the extrarenal vascular beds. Ocular structures affected by the thrombotic microangiopathy of haemolyticuraemic syndrome have been occasionally described..$^{4-8}$ The present case appears to be the first for haemolytic-uraemic syndrome following cyto-

Correspondence: Ramón Díaz de Otazu, M.D., Departamento de Anatomía Patológica, Hospital Txagorritxu, 01009 Vitoria, Spain.

Accepted: 11 January 1993 megalovirus infection with documented retinal histology at autopsy.

\section{Case report}

A 33 year old women presented with a 3 week history of fever. The patient's medical history was unremarkable. On the following days after admission to the hospital, the patient developed periorbital oedema, hypoproteinaemia with no evidence of proteinuria and decreased visual acuity which was attributed to an acute exudative chorioretinitis with peripapillary retinal oedema. Blood pressure was normal. Treatment with corticosteroids was unsuccessful and acute renal failure developed. The serum creatinine level was $707 \mu \mathrm{mol} / 1$ (normal $<123 \mu \mathrm{mol} / \mathrm{l})$. Laboratory tests disclosed microangiopathic haemolytic anaemia (haemoglobin $6.5 \mathrm{~g} / \mathrm{dl}$ ) reticulocytes $5.8 \%$, platelet count $106 \times 10^{9} / 1$, schistocytes ++++ , haptoglobin $<0.25 \mu \mathrm{mol} / 1$ (normal $0.27-1.21 \mu \mathrm{mol} / \mathrm{l}$ ) and 
elevated IgM-specific cytomegalovirus antibody. Cultures of the samples were not done. Lupus anticoagulant was not performed but bloodclotting tests including activated partial thromboplastin time were within normal limits. Serological tests for syphilis (VDRL) and human immunodeficiency virus (HIV) infection were negative. Skin changes attributable to scleroderma were not present and antinuclear antibodies were negative. The patient did not respond to haemodialysis and plasma exchange. The renal biopsy revealed extensive glomerular involvement with over $90 \%$ showing thrombotic microangiopathy. Focal IgM, C3 and fibrin deposits were also observed. Some small arteries were completely occluded by thrombosis. Refractory renal failure was followed by severe encephalopathy, generalized seizures and blindness. The patient died of hypoxic-ischaemic encephalopathy a week following the onset of alteration of consciousness. A diagnosis of haemolyticuraemic syndrome and cytomegalovirus infection was made.

Postmortem examination. Microscopically, glomerular thrombotic microangiopathic features were identified. Apart from the kidneys, intravascular thrombosis was seen in the small feeding arteries emerging from the ganglion cell layer of the retina (Figure 1). Signs of ischaemic necrosis were evident in most ganglion cells (Figure 2). Neither inflammatory infiltration nor nuclear inclusions of cytomegalovirus infection were seen in any of the multiple sections examined by light microscopy. In situ hybridization with specific probes for cytomegalovirus (Enzo Biochem) was negative. Cerebral oedema and severe diffuse hypoxic/ ischaemic changes were widespread in the central nervous system.

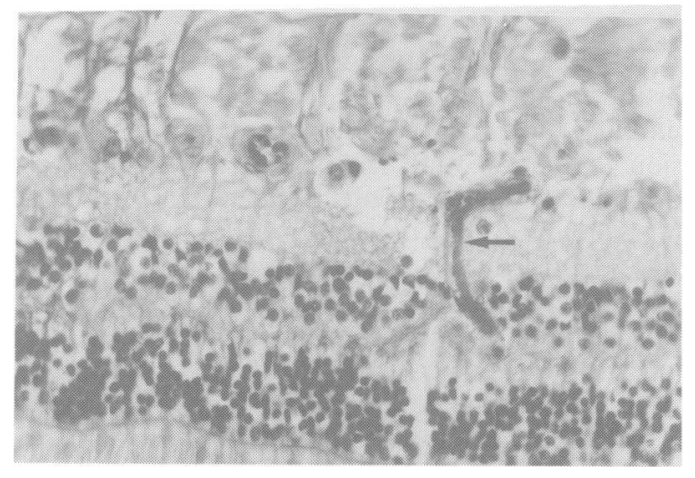

Figure 1 Thrombosis of a small arterial vessel (arrow) in the ganglion cell layer of the retina (longitudinal section) (haematoxylin and eosin $\times 25$ ).

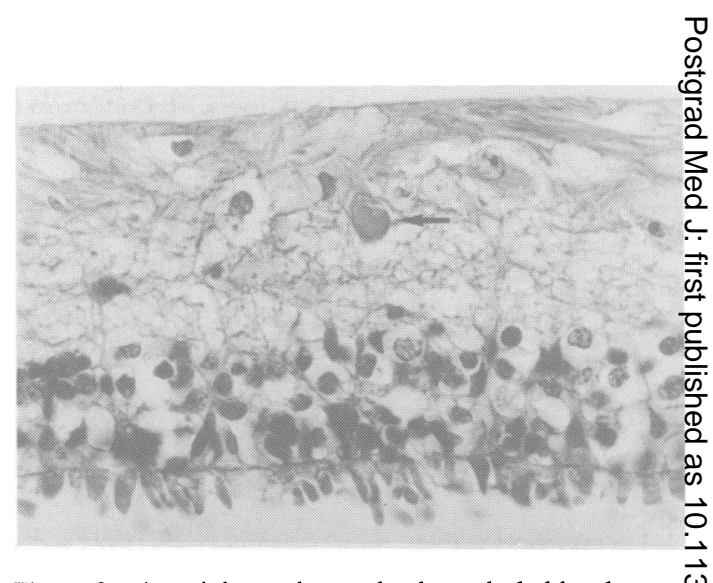

Figure 2 Arterial vessel completely occluded by thrombosis (arrow) (transversal section). Note degenerative changes in ganglion cells (haematoxylin and eosin $\times 25$ ).

\section{Discussion}

The haemolytic-uraemic syndrome is a rare condition characteristically occurring in children over 4 음 years of age. In an autopsy series, Zollinger and Mihatsch $^{2}$ estimated an incidence rate of $1 / 25000$. A sex predominance has not been reported.

Different agents have been implicated in the $\stackrel{\bar{\rho}}{\stackrel{9}{+}}$ pathogenesis of haemolytic-uraemic syndrome, $\vec{\theta}$ particularly infection with verocytotoxi producing Escherichia coli which has been demo strated in $75 \%$ of children with this disease. $\stackrel{39}{*}$ Shigella and Campylobacter-associated haemolytic-uraemic syndrome can also occur. ${ }^{3,9,10}$ Viral infections (mumps, chicken-pox, arbovirus, $\frac{\circ}{\odot}$ HIV), ${ }^{10,11}$ use of oral contraceptives, pregnancy, $\stackrel{\mathbb{Q}}{\unrhd}$ immune dysfunction, antineoplastic therapy, lupus $\overrightarrow{\vec{O}}$ erythematosus, scleroderma, malignant hyperten- 3 sion and radiation therapy are some of the possible associated conditions with adult forms of haemolytic-uraemic syndrome. ${ }^{1,10-12}$

The patient in our study presented with a 3 week febrile episode and seropositivity for cyto- $\frac{5}{3}$ megalovirus infection. To our knowledge, a postinfection form of haemolytic-uraemic syndrome $\frac{\rho}{3}$ to cytomegalovirus has not been previously de-

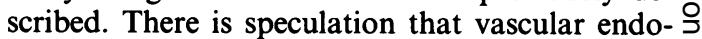
thelial cell injury from viral infections, bacterial $\frac{D}{2}$ toxins or immune complexes is the primary event. ${ }^{3,4,13}$ This endothelial cell injury might then $\tilde{N}_{\mathcal{O}}$ release proaggregatory substances and initiate the formation of platelet-fibrin microthrombi. ${ }^{4}$ It is ${ }_{N}$ not clear why thrombotic microangiopathy always $\omega$ involves the renal, but usually spares the extrarenal, vascular beds.

Although several authors have emphasized the importance of neurological symptoms in haemo-? lytic-uraemic syndrome, ${ }^{9,14,15}$ the involvement of $\frac{T}{0}$ the central nervous system in this disorder is less $\frac{O}{\mathbb{D}}$ frequent and of lesser intensity than that in throm- 
botic thrombocytopenic purpura. The changes noted in our patient were nonspecific and consisted of oedema and hypoxic damage. Metabolic alterations that occur during haemolytic-uraemic syndrome have been implicated in the pathogenesis of the central nervous system dysfunction. ${ }^{14}$

Ocular involvement in haemolytic-uraemic syndrome has been occasionally recognized.$^{4-8}$ In two patients, sight was lost because of thrombotic microangiopathy involving the optic nerves and retinae, ${ }^{4,5}$ and one patient presented with reversible retinal thrombotic microangiopathy and temporary blindness. ${ }^{6}$ In the review of 16 patients by Morel-Maroger et al., ${ }^{7}$ there were striking ocular abnormalities, including soft exudates, papilloedema and inflammatory retinal detachment. Visual abnormalities include vitreous haemorrhage, retinal detachment, optic nerve atrophy and occasionally cortical (central) blindness.

In the case reported here, platelet-fibrin microthrombi found in the small retinal vessels were the

\section{References}

1. Remuzzi, G. HUS and TTP: variable expression of a single entity. Kidney Int 1987, 32: 292-308.

2. Zollinger, H.U. \& Mihatsch, M.J. Thrombotic microangiopathy. In: Zollinger, H.U. \& Mihatsch, M.J. (eds). Renal Pathology in Biopsy. Springer Verlag, Berlin, 1978, pp. 499-506.

3. Richardson, S.E., Karmali, M.A., Becke, L.E. \& Smith, C.R. The histopathology of the hemolytic uremic syndrome associated with verocytotoxin-producing Escherichia coli infections. Hum Pathol 1988, 19: 1102-1108.

4. Siegler, R.L., Brewer, E.D. \& Swartz, M. Ocular involvement in hemolytic-uremic syndrome. $J$ Pediatr 1988, 112: 594-597.

5. Gum, K.G., Carter, K.D. \& Vine, A.K. Massive bilateral retinal vascular occlusion secondary to thrombocytopenic purpura. Retina 1988, 8: 185-187.

6. Weyl, M., Rivard, G.E., O'Reagan, S. et al. Haemolytic uremic syndrome: treatment with plasma, vitamin $E$ and cod liver oil. Int Pediatr Nephrol 1983, 4: 243-245.

7. Morel-Maroger, L., Kanfer, A., Solez, K., Sraer, J.-D. \& Richet, G. Prognostic importance of vascular lesions in acute renal failure with microangiopathic hemolytic anemia (hemolytic-uremic syndrome): Clinicopathologic study in 20 adults. Kidney Int 1979, 15: 548-558. cause of necrosis of the ganglion cells and blindness. We have recently documented another case of haemolytic-uraemic syndrome with loss of visual acuity in a 16-year-old boy with acute monocytic leukaemia as a complication of chemotherapy and irradiation. As fundoscopic examinations were not carried out, the loss of visual acuity was attributed to chorioretinitis due to Toxoplasma as this organism was shown to be the cause of encephalitis in the postmortem examination. Both cases illustrate that the optic nerve and retina need to be included in the list of possible extrarenal structures affected by thrombotic microangiopathy in haemolytic-uraemic syndrome.

\section{Acknowledgement}

The authors thank Marta Pulido, M.D., for editorial assistance and copy editing.

8. Haemeter, W. Presumed thrombotic thrombocytopenic purpura associated with bilateral serous retinal detachments. Am J Ophthalmol 1988, 105: 421-422.

9. Neild, G. The haemolytic uremic syndrome: a review. $Q J$ Med [New Series] 1987, 63: 367-376.

10. Loirat, C., Sonsino, E., Varga Moreno, A. et al. Hemolytic uremic syndrome: an analysis of the natural history and prognostic features. Acta Paediatr Scand 1984, 73: 505-514.

11. Jokela, J., Flynn, T. \& Henry, K. Thrombotic thrombocytopenic purpura in human immunodeficiency virus (HIV)-seropositive homosexual man. Am J Hematol 1987, 25: $341-345$.

12. Kwaan, H.C. Miscellaneous secondary thrombotic microangiopathy. Semin Hematol 1987, 24: 141-147.

13. Rose, P.E., Taylor, C.M. \& Kavi, J. Pathogenesis of haemolytic uraemic syndrome. Lancet 1988, 2: 580.

14. Bale, F., Jr, Brasher, C. \& Siegler, R.L. CNS manifestations of the hemolytic-uremic syndrome. Am J Dis Child 1980, 134: $869-872$.

15. Sheth, K.J., Swick, H.M. \& Haworth, N. Neurological involvement in hemolytic-uremic syndrome. Ann Neurol 1986, 19: 90-93. 